\title{
User community preferences for climate change mitigation and adaptation measures around Hainich National Park, Germany
}

\author{
Sandra Rajmis*, Jan Barkmann, Rainer Marggraf \\ Institute of Agricultural Economics and Rural Development, Environmental and Resource Economics, \\ Georg-August-Universität Göttingen, Platz der Göttinger Sieben 5, 37073 Göttingen, Germany
}

\begin{abstract}
In contemporary media discourse, suggestions for publicly mandated climate change mitigation or adaptation measures are frequently challenged from a cost perspective. However, empirical data on the actual economic appreciation of local mitigation and adaptation measures expressed as citizen willingness-to-pay (WTP) are scarce. In this paper, we report results of a preference survey using a choice experiment (CE) that quantifies economic preferences for biodiversitybased climate change mitigation and adaptation in the region surrounding Hainich National Park (Thuringia, Germany). A representative sample of 302 respondents - the majority of them frequent Hainich forest visitors - was interviewed in autumn 2006. Nested logit analysis showed that respondents state a substantially positive WTP for climate change mitigation by afforestation $(p<0.001)$. If converted to WTP for an additional sequestration of carbon that average German citizens emit as $\mathrm{CO}_{2}$, a monetary value of $7.34 € \mathrm{yr}^{-1} \mathrm{t} \mathrm{C}^{-1}$ is obtained. For increasing forest resistance and resilience against insect pests and storms (climate change adaptation) a WTP of $27.54 € \mathrm{yr}^{-1}(\mathrm{p}<0.001)$ is obtained, and $16.83 € \mathrm{yr}^{-1}(\mathrm{p}<0.001)$ is obtained for increasing the general resilience and resistance of forest ecosystems to environmental stressors. Respondents support moderate programs to eradicate invasive plants when compared to more aggressive eradication measures. Due to the lack of comparable studies, it can only be conservatively assumed that WTP would be lower if mitigation and adaptation measures were to be implemented in forests not, or only rarely, used by respondents. As all proposed means for climate change mitigation and adaptation contribute to local forest ecosystem biodiversity, the results of the study advocate the realization of measures that potentially benefit both climate policy and regional conservation concerns.
\end{abstract}

KEY WORDS: Economic valuation · Choice experiment · CE · Willingness-to-pay · WTP · Afforestation · Insect pests · Climatic extremes · Resilience · Ecological biodiversity

\section{INTRODUCTION}

A very substantial body of scientific evidence indicates that the Earth's climate is rapidly changing, mainly as a result of increasing anthropogenic greenhouse gas emissions (e.g. Levitus et al. 2000, Ruddiman et al. 2005, IPCC 2007). Influential political actors frequently question the expediency of the Kyoto Protocol and other suggested climate change mitigation targets that require substantial reductions of greenhouse gas (GHG) emissions. Usually economic reasons are cited, e.g. more ambitious measures would 'cause serious harm to the U.S. economy' (Bush 2001, EIA 2002). In contrast, Stern (2006) claims that the costs of action need not be prohibitive, and would be much smaller ( $1 \%$ of GDP) than the damage caused by climate change (5 to $20 \%$ GDP) in high emission scenarios in several decades from now. The Stern review has also been criticized several times (e.g. Cole 2007, Nordhaus 2007, Tol 2007). In view of conflicting macroeconomic projections, we may safely assume that the willingness of political decision-makers to initiate costly climate protection measures is influenced by 
evidence of the willingness of consumers and citizens (voters) to pay for such measures. Surprisingly few willingness-to-pay (WTP) studies are available (Table 1). However, an improved integration of economic and social science expertise in climate research is critically called for (Msangi et al. 2006).

In this paper, we present results of a survey conducted in several villages and 2 smaller towns around Hainich National Park (Thuringia, Germany). The results document a substantial WTP for differing types of regional climate change mitigation and adaptation measures. We first explain the main features of the choice experiment (CE) method and its analysis (Sections 2 \& 3). Empirical results and WTP estimates follow in Section 4; these are discussed in Section 5.

\section{METHODS}

\subsection{Choice experiment}

The choice experiment (CE) method is based on the characteristics theory of value (Lancaster 1966) and on random utility theory (McFadden 1973, Adamowicz et al. 1998a). CEs were initially developed in marketing research to estimate economic preferences for characteristics (attributes) of new products. They have proven to be a versatile method for the estimation of economic values regarding the environment (Hensher et al. 2005). The CE method relies on social science surveys for data collection, as does the related contingent valuation method (Bateman et al. 2002, Perrings 1995a). Instead of asking questions such as 'Are you willing to pay $\mathrm{X} €$ to prevent $Y$ effect of climate change?', CEs focus on trade-offs among different policy scenarios with different environmental outcomes. CEs have been recognized to be particularly suitable for analyzing different options for mitigation of and adaptation to climate change (Australian Greenhouse Office 2004, p. 19).

The choice scenarios (options) of a CE are differentiated through the attribute levels (characteristics) possible in a policy scenario. In CE face-to-face applications, the scenarios are often printed on cards and presented to respondents. We presented 3 of these cards (the choice set; Fig. 1) to respondents, and asked them to choose the option they wished to see implemented. Two cards characterised the generic policy options A and B, and the third card represented the current situation (status quo). The price (cost) of each policy option was included as one attribute on the choice cards, and operationalised as a mandatory tax payment. For the status quo option, the cost was always zero. The specific combination of attribute levels on the cards was determined by experimental design rules ${ }^{1}$. Some more details on the econometric estimation of CE models are given in Section 3.1.

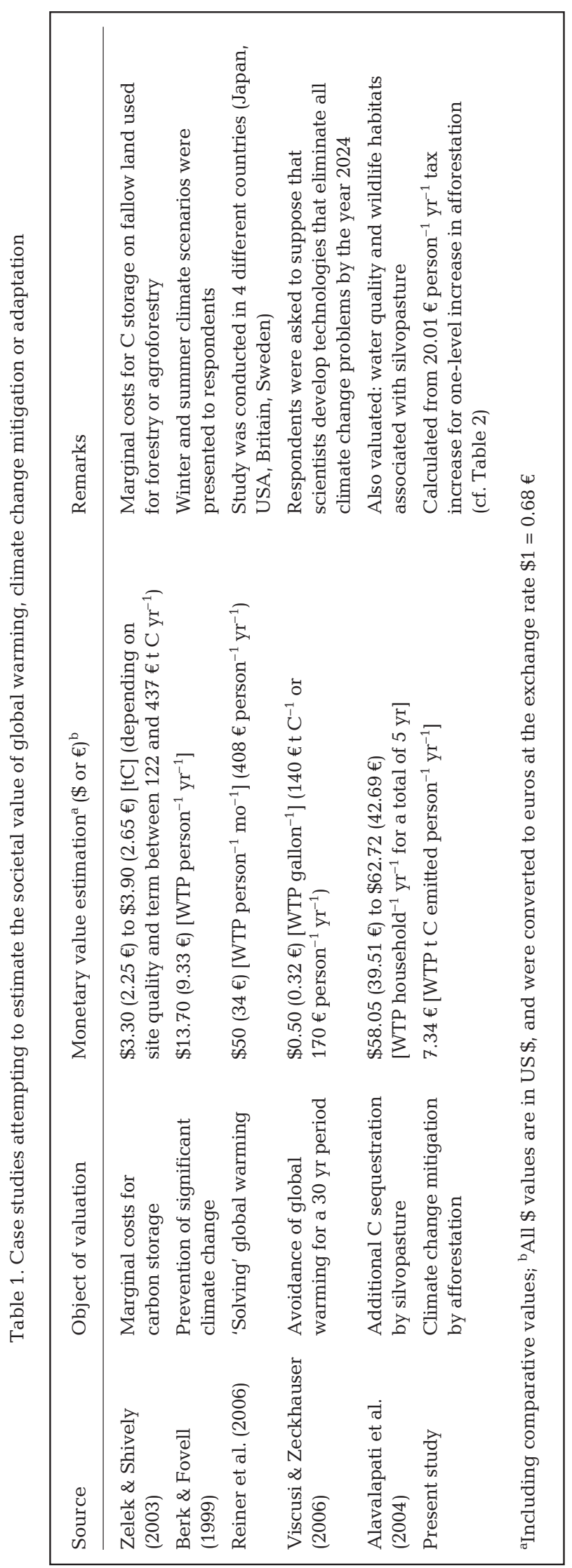




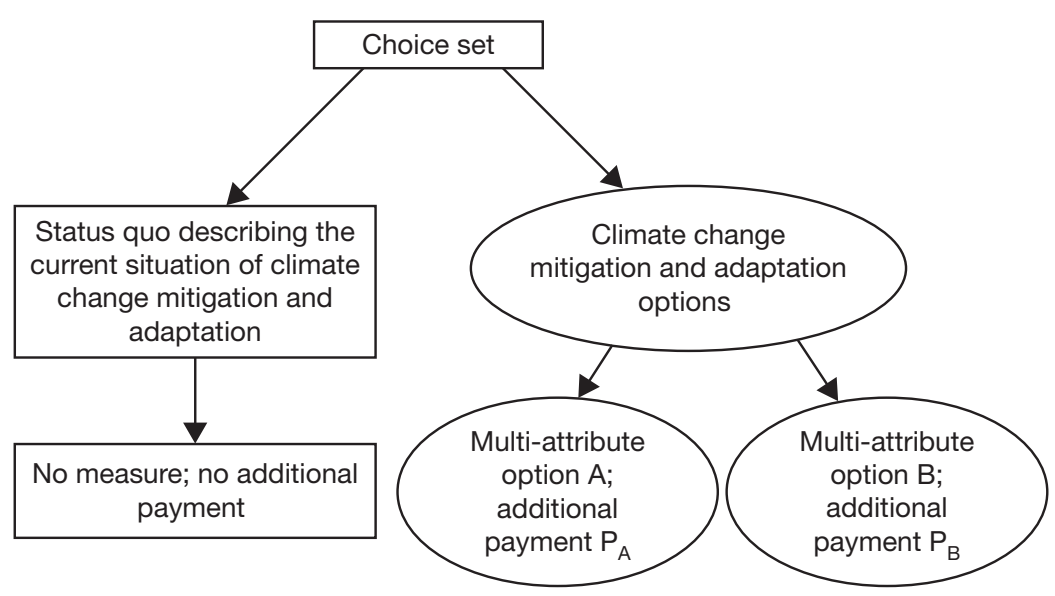

Fig. 1. Structure of the choice experiment: a choice set with one status quo option and 2 multi-attribute climate change mitigation and adaptation options are presented to respondents

1995, Meyer et al. 2003). Generally, regenerated forests store less carbon than natural forests, even at maturity (Buchmann \& Schulze 1999).

\subsection{Measures of climate change mitigation and adaptation}

To ensure that respondents properly understood the climate change mitigation and adaptation policy scenarios, we employed 2 strategies. First, we conducted 16 semi-structured in-depth interviews to elucidate the perceptions held by typical respondents on issues such as climate change, risks from increasing weather anomalies, invasive species and environmental risks in general (Rajmis \& Barkmann 2007). Sec-

\subsection{Study site}

All mitigation and adaptation scenarios in this study were based upon the Hainich area in Thuringia, comprising the Hainich National Park (Hainich NP, $7600 \mathrm{ha})$, and the wider Hainich forest ecosystem ( 16 000 ha, including the NP). It is the largest coherent deciduous forest in Germany. The national park is used for recreation, tourism and partly just as natural habitat. Hainich NP is dominated by Fagus sylvatica L. (European beech), mostly in uneven-aged stands that have not been harvested, thinned or used at least since 1997. From 1964 to 1997, the forest was part of a military training area where only a few single trees of high value were cut (Mund 2004).

Nevertheless, the unmanaged sites (90\% of Hainich NP) do not represent a primary forest because nearly all forests in central Europe are influenced by historical forest use and management. For at least $140 \mathrm{yr}$ (equivalent to one rotation period), all parts of the Hainich forest were managed at varying intensities as shelterwood forests or with a selection system (Mund 2004). For the Hainich forest ecosystem, a yearly average net carbon uptake as high as 480 to $580 \mathrm{~g} \mathrm{C} \mathrm{m}^{-2}$ $\mathrm{yr}^{-1}$ was calculated (Knohl et al. 2003). Only a fraction of this can be attributed to long-term soil storage. Timber carbon pools are similar to other values for primary beech stands under favourable conditions (Korpel

1This procedure results in a few choice cards that request an additional tax payment even though the environmental attributes appear worse than the status quo (see Table 3). However, because respondents are always free to choose the status quo option at zero cost, the choice set always offers meaningful choices ond, we made sure that any mitigation or adaptation attribute made sense to respondents in terms of their personal values and interests. To explicate the benefits that respondents would obtain from an implementation of the proposed mitigation and adaptation options, we used an ecosystem service approach developed specifically for the valuation of 'unfamiliar' environmental attributes (Barkmann et al. 2008). In this approach, the focus shifts from a valuation of technically described changes in ecosystem structure or functioning (or the measures that bring about these changes) to the valuation of ecosystem service effects, i.e. benefits to people.

\subsubsection{Mitigation: additional carbon sequestration by afforestation}

Pre-study interviews revealed that respondents did not consider the unit 'tons of sequestered carbon per year' as a meaningful quantification of a climate change mitigation attribute brought about by a forest ecosystem. If explained in terms of their own annual $\mathrm{CO}_{2}$ emissions ( $10 \mathrm{t} \mathrm{C} \mathrm{yr}^{-1}$ person $^{-1}$ in Germany), however, respondents could relate much more easily to a quantitative aspect of climate change mitigation measures. This result prompted us to focus explicitly on individual contributions towards climate change mitigation. Thus, we decided to elicit preferences quantified in terms of per person $\mathrm{CO}_{2}$ emission equivalents. Although climate change is a global issue, the regional scope of our study prompted us to search for Hainich forest-based measures that could serve as 'vehicles' to effectuate climate change mitigation. In the following we describe the scientific basis for the quan- 
tification of the respective CE attribute levels on regional afforestation measures.

First, the C-sequestration of the existing forest had to be assessed. Robertson \& Vitousek (1981) found a long-term sequestration rate of $9.4 \mathrm{~g} \mathrm{C} \mathrm{m}^{-2} \mathrm{yr}^{-1}$ for the soil compartment of a 250 yr old oak forest. Much lower values $\left(2.4 \mathrm{~g} \mathrm{C} \mathrm{m}^{-2} \mathrm{yr}^{-1}\right.$ ) for a $200 \mathrm{yr}$ old oakhickory-pine stand (Switzer et al. 1979) as well as much higher values (60 to $80 \mathrm{~g} \mathrm{C} \mathrm{m}^{-2} \mathrm{yr}^{-1}$ ) for an $80 \mathrm{yr}$ old stand (Jenkinson 1971) have been measured in an old field succession (long-term agriculture to oak forest). In absence of more detailed long-term C-sequestration rates, we adopted a rate of $9.2 \mathrm{~g} \mathrm{C} \mathrm{m}^{-2} \mathrm{yr}^{-1}$ for Hainich forest, i.e. slightly lower that the rate determined by Robertson \& Vitousek (1981). For roughly 16000 ha of Hainich forest, this results in C-sequestration equivalent to the emissions of 540 average German citizens (for calculation, see Appendix 1).

As alternatives to the status quo, we offered respondents 2 different local afforestation measures: one that results in the sequestration of the $\mathrm{CO}_{2}$ emitted by an additional 90 individuals (Level 1; resulting sequestration of 630 individuals), and one that sequesters twice as much (Level 2; resulting sequestration of 720 individuals). At $\mathrm{C}$-sequestration rates typical for young aggrading forests $\left(6.2 \mathrm{t} \mathrm{CO}_{2} \mathrm{ha}^{-1} \mathrm{yr}^{-1}\right.$; Deckmyn et al. 2004), around 145 ha of afforestation area would be required for a Level 1 measure, and 290 ha for Level 2 (for calculation, see Appendix 1). The size of these 2 afforestation measures seems somewhat arbitrary. The measures were chosen (1) to convey the idea that a substantial improvement of $\mathrm{C}$-sequestration of Hainich forest could be achieved, but (2) without requiring areas of land so extensive as to cause negative emotional reactions.

To calculate the shadow price of C-sequestration, we first calculated the marginal WTP (mWTP) for a 1-level change in the afforestation attribute per respondent. Because of the strategy to relate preferences for Csequestration to personal emissions, i.e. to individual responsibility for climate change, this mWTP is then attributed to the individual average annual $\mathrm{C}$ emission

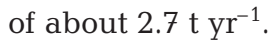

\subsubsection{Adaptation: removal of potentially invasive plants}

Several invasive species are likely to benefit from expected global climate change trends (Rejmanek 2000). Invasive plants are regarded as the second largest threat to biodiversity in Central Europe (Kowarik 2003). Besides competing with native species for habitats and resources, invasive species can harm forestry and agriculture. For instance, the giant hog- weed Heracleum mantegazzianum is a host for the crop pathogen Sclerotina sclerotina (Williamson \& Forbes 1982), can reduce species richness of invaded habitats by 40 \% (Pyšek \& Pyšek 1995), and is known to produce human-toxic substances in its sap (JaspersenSchib et al. 1996).

Our pre-study showed that respondents felt threatened by non-native plants, particularly by the giant hogweed. Thus, we decided to use Heracleum mantegazzianum to explain risks of invasive plants that are known to be harmful. We used 2 attribute levels Level 1 represented the current practice (status quo), i.e. removal of invasive plants in particular cases where negative effects are known. Level 2 represented the alternative measure, i.e. large-scale removal of invasive plants regardless of whether they have negative effects or not.

We had no a priori hypothesis that Level 2 constituted, on average, a utility gain compared with the status quo.

\subsubsection{Adaptation: increasing forest resistance and resilience to pests and storms}

Shifts in life cycles of pests (e.g. beetles) can result from climate change (Parmesan 2006). One example is the mountain pine beetle Dendroctonus ponderosae in the Rocky mountains in the USA which now only takes one year per generation rather than its previous $2 \mathrm{yr}$ life cycle (Logan et al. 2003). This, in turn, can increase infestation rates with the pine blister rust fungus Cronartium ribicola. Also wind storm related risks rise for German forests (Zebisch et al. 2005, p. 6). Stochastic dynamic models provide evidence that asynchronicity of species responses can ensure that species-rich forest ecosystems provide climate change adaptation services because they are able to adjust better to the changing environmental conditions (cf. Yachi \& Loreau 1999).

Our qualitative interviews revealed that respondents perceived forests as threatened by insect pest outbreaks, particularly from bark beetles Scolytida spp. and through damage by caterpillers, and by storm events. We bundled these rather well-known threats into one attribute on forest resistance and resilience (Widerstandskraft) to pests and storms. Indicating that this is a simplification of a more complex ecological reality, we explained that better resistance and resilience could be effectuated by a higher diversity of site-adapted tree species.

We offered 3 attribute levels ranging from 'high' resistance and resilience to insect pests and storms by planting additional site-adapted tree species, to 'low' resistance and resilience characterised by low diver- 
sity of site-adapted tree species. In the Hainich project region, several monoculture forest tree plantations exist in which respective 'diversification measures' could be implemented.

\subsubsection{Adaptation: increasing general forest ecosystem resistance and resilience}

Because not all climate-change related effects are apparent today, biological insurance services in the face of new, fundamentally uncertain or unknown risks (Barkmann \& Marggraf 2007, Rajmis et al. 2008) are called for. Thus, we included an attribute on increasing general forest ecosystem resistance and resilience. The WBGU (German Advisory Council) on Global Change (WBGU 2000) suggests a precautionary risk management strategy to handle as-yet undiscovered risks. This argument is often implicitly used when ecologists and environmental economists suggest preserving as many species as possible, thereby hoping for an ecological insurance effect (Perrings 1995b, Gitay et al. 1996, Myers 1996, Edwards \& Abivardi 1998, Yachi \& Loreau 1999). From an ecosystem science perspective, species diversity provides key information on the processing of matter and energy within an ecosystem, and is an indispensable factor of the capacity of the ecosystem to self-organise in the face of internal or external changes (Kutsch et al. 2001).

Soil organisms are essential for the fundamental functioning of terrestrial ecosystems (e.g. Balser et al. 2002). One group of species whose diversity has been linked to the stability properties of forest are the mycorrhizae (Bot \& Benites 2005). Mycorrhizal fungi play a key role in the uptake of nutrients and water (Galvan et al. 2007), and contribute to the maintenance of soil porosity and organic matter content (Dighton 2003).

We chose a measure of soil organism diversity to indicate the capacity of the Hainich forests to selforganise, and thus to provide 'general' forest ecosystem resistance and resilience over other biota, as soil organisms are not visible. Changes in tree or herb diversity, for example, may have triggered the statement of additional aesthetic preferences in our nonexpert respondent sample. This would have made it more difficult to interpret WTP statements for an attribute on general forest resilience. Interviewers briefly explained the importance of mycorrhizae, and their role in generalised ecosystem resilience and resistance in the face of as yet unknown environmental threats. Furthermore, it was explained that forest thinning may improve mycorrhizae numbers, and without being specific about improvement measures, explained that stands with lower mycorrhizal diversity exist in the Hainich project region in which mycorrhizal diversity could be fostered.
We offered 3 levels to respondents: 'high', 'medium' and 'low' resistance and resilience to unknown threats. The attribute level description for the option only included this quantification. It did not mention the mycorrhizal indicator nor did it hint at potential forestry measures (see Fig. 2).

Changes between levels are difficult to bring about by traditional forestry measures for many forests. Still, mycorrhizal diversity responds to changes in forest structure (Kernaghan et al. 2003), at least partly to inoculation in afforested stands (Menkis et al. 2007), and changes in atmospheric carbon inputs (Talbot et al. 2008). Because we restrict the interpretation of the attribute to adaptive ecosystem insurance services (S. Rajmis et al. unpubl.), the fact of mycorrhizal diversity can, in principle, be manged suffices to justify the utilisation of mycorrhizal diversity as a plausible indicator of positive biodiversity effects on general forest resistance and resilience. Although few respondents were knowledgeable about the importance of tree-mycorrhizae interactions, our extensive preliminary studies clearly showed that the role of functional diversity and functional redundancy for ecological insurance (McCann 2000) was familiar to respondents if described in non-technical terms (Rajmis \& Barkmann 2007).

\subsection{Preparation and administration of the CE study}

From attributes and attribute levels (Table 2), we generated an orthogonal main effects design (Hensher et al. 2005, p. 115) with 64 different choice cards using the mix and match procedure by Chrzan \& Orme (2000). The 64 choice cards were, in turn, randomly assigned to 4 blocks of 8-choice sets. Interviewers alternated blocks systematically with each consecutive respondent being assigned to the choice sets of 1 block.

The CE main survey $(\mathrm{n}=302)$ was preceded by qualitative preliminary studies $(n=16$; Rajmis \& Barkmann 2007), pre-test interviews $(n=57)$, and a pilot study $(n=106)$. Pilot study and main study were conducted as a household survey using face-to-face interviews in 19 of the 30 villages adjacent to Hainich National Park, in the administrative districts Wartburg and UnstrutHainich, and in the neighbouring towns of Eisenach (pop. 43300) and Bad Langensalza (pop. 18390) (Thuringia). To sample private households, we used the random route method (Kromrey 2006). Interviewers were given exact points of departure in a certain street beginning with a defined starting point, and had rules about the direction to walk, which houses to call on and other details on establishing contacts to survey participants. 
Table 2. Climate change mitigation and adaptation measures/indicators used in the choice experiment, translated from the German version of the questionnaire. Coding in parentheses if not directly given; ${ }^{\mathrm{SQ}}$ : status quo

\begin{tabular}{|c|c|c|c|c|}
\hline Attribute & Measure/Indicator & \multicolumn{3}{|c|}{ Level of change of mitigation or adaptation measure/indicator } \\
\hline \multicolumn{5}{|c|}{ Climate change mitigation } \\
\hline Afforestation & $\begin{array}{l}\text { Quantified by carbon sequestra- } \\
\text { tion/emission equivalents per } \\
\text { capita }\end{array}$ & $\begin{array}{l}\text { Sequestration/emission } \\
\text { equivalents of } 540 \\
\text { persons }(540)^{\mathrm{SQ}}\end{array}$ & $\begin{array}{l}\text { Sequestration/emission } \\
\text { equivalents of } 630 \\
\text { persons ( } 630)\end{array}$ & $\begin{array}{l}\text { Sequestration/ } \\
\text { emission equivalents } \\
\text { of } 720 \text { persons (720) }\end{array}$ \\
\hline \multicolumn{5}{|c|}{ Climate change adaptation } \\
\hline Invasive plants & $\begin{array}{l}\text { Removal of invasive non-native } \\
\text { plants }\end{array}$ & $\begin{array}{l}\text { Only if harmful and in } \\
\text { particular cases }(1)^{\mathrm{SQ}}\end{array}$ & \multicolumn{2}{|c|}{ Large scale removal if harmful or not (2) } \\
\hline Pests and storms & $\begin{array}{l}\text { Planting of better site-adapted } \\
\text { tree species }\end{array}$ & $\begin{array}{l}\text { Low resistance and } \\
\text { resilience (1) }\end{array}$ & $\begin{array}{l}\text { Medium resistance and } \\
\text { resilience }(2)^{\mathrm{SQ}}\end{array}$ & $\begin{array}{l}\text { High resistance and } \\
\text { resilience (3) }\end{array}$ \\
\hline $\begin{array}{l}\text { General forest eco } \\
\text { system resilience }\end{array}$ & $\begin{array}{l}\text { Changes in diversity of mycor- } \\
\text { rhizal fungi }^{\mathrm{a}}\end{array}$ & $\begin{array}{l}\text { Low resistance and } \\
\text { resilience (1) }\end{array}$ & $\begin{array}{l}\text { Medium resistance and } \\
\text { resilience }(2)^{\mathrm{SQ}}\end{array}$ & $\begin{array}{l}\text { High resistance and } \\
\text { resilience (3) }\end{array}$ \\
\hline Cost (price) & $\begin{array}{l}\text { Income change per month per } \\
\text { person by a dedicated tax }\end{array}$ & \multicolumn{3}{|c|}{$0 €^{\mathrm{SQ}}, 5 €, 10 €, 20 €, 35 €, 50 €, 60 €, 80 €(=$ coding $)$} \\
\hline
\end{tabular}

Target respondents were all German-speaking individuals who were at least $18 \mathrm{yr}$ old. Target persons were identified by the 'last-birthday' method, i.e. the person with the most recent birthday was sampled (Rizzo et al. 2004). All interviews (pilot and main study) were conducted by 5 trained university students.

Of the respondents contacted, 471 declined to give an interview. Of the successfully contacted 302 households, 282 respondents completed the choice task. 20 respondents $(6.6 \%)$ protested the choice experiment (see Adamowicz et al. 1998b). Eleven of these protested against the cost attribute (rejection of any extra tax, extremely skeptical attitude towards implementation of the proposed measures); 3 respondents refused any measure in general (strongly disliked) involving Hainich National Park, while another 2 respondents had a strict non-interference attitude towards the national park. Only 2 respondents protested the proposed mitigation and adaptation measures. Finally, 2 individuals clearly did not understand the choice task. An average interview took $35 \mathrm{~min}$. In addition to a suite of attitudinal questions not included in this paper (Rajmis et al. 2008), we asked respondents to rate the importance of the CE attributes explicitly ('most important $=5$ ' to 'completely unimportant $=1$ '). A sample of choice cards is shown in Fig. 2. See Fig. 4 for details on rating.

\section{ECONOMETRIC ANALYSIS}

We assume an additive utility function linear in parameters with respect to the attribute levels as coded in
Table 2 (see also Section 2.1). The utility function can be separated into an observable component $V_{\text {in }}$ and unobservable (error) component $\varepsilon_{\text {in }}$ :

$$
U_{\text {in }}=V_{\text {in }}+\varepsilon_{\text {in }}
$$

where $U_{\text {in }}$ is the total utility of option $i$ for individual $n$. The probability $(\mathrm{Pr})$ that individual $n$ will choose option $i$ over option $j$ within the complete choice set $C$ is given by:

$$
\operatorname{Pr}_{i n}=\operatorname{Pr}\left(V_{i n}+\varepsilon_{i n}>V_{j n}+\varepsilon_{j n} \text { all } j \in C\right)
$$

If a deterministic utility component $V_{1}$ is hypothesized to be a linear function of attribute $Z_{1}$ itself, plus an interaction term of the attribute $Z_{1}$ with an individually varying socio-demographic variable $A, V_{1}$ can be expressed as:

$$
V_{1}\left(Z_{1}, A\right)=C_{A} Z_{1} A+C_{1} Z_{1}
$$

where $c_{A}$ is the utility coefficient of the interaction term (Barkmann et al. 2007). In the econometrically estimated utility models, a positive coefficient $C$ indicates a positive influence of the respective term on choices, and thus on utility. To reduce collinearity between the interaction term and the non-interacted attribute term, the socio-demographic variable $A$ can be standardized before being multiplied by $Z_{1}$. The vector of the utility coefficient is usually estimated with maximum likelihood estimation techniques. Usually the estimated choice models include an alternative specific constant (ASC) that picks up systematic differences in choice patterns between the 3 choice cards. The ASC was coded 'zero' for cards A and B, and ' 1 ' for the status quo option (status quo-ASC). 


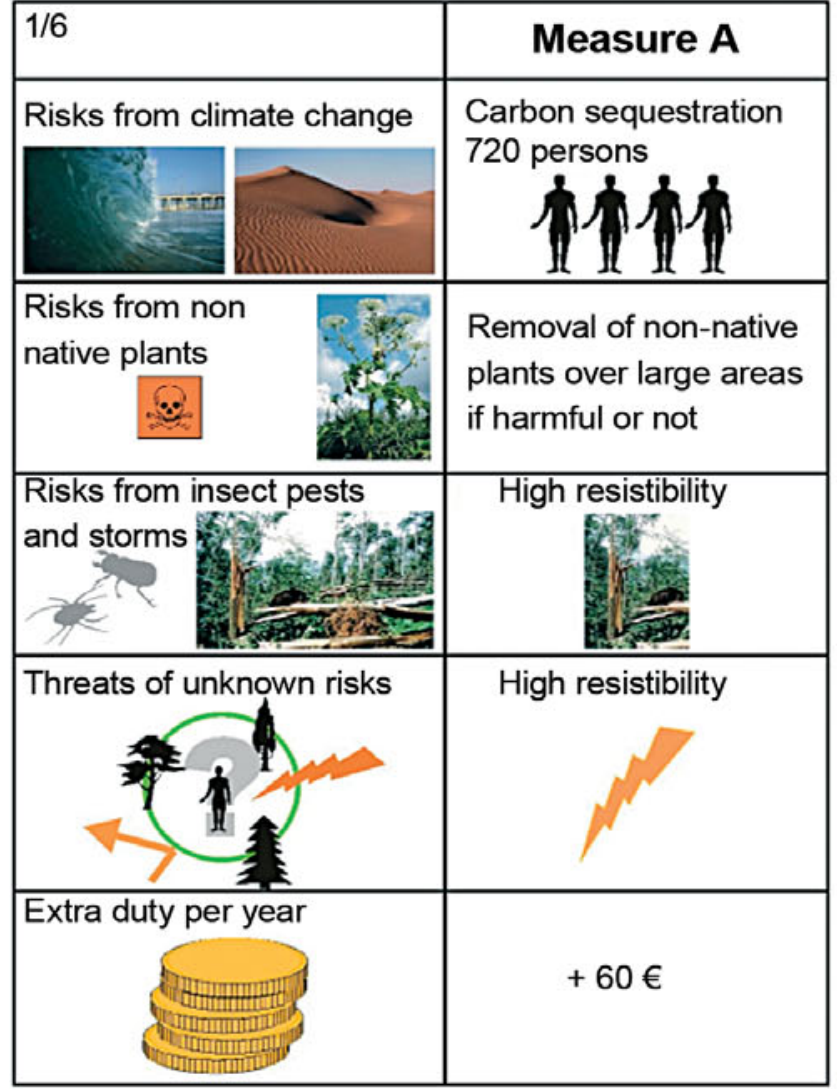

Fig. 2. A sample set of choice cards (translated from the original German version). Forest ecosystem resistance and resilience (Widerstandskraft) is translated as 'resistibility'

Preliminary analyses unveiled a risk of violation of the independence from irrelevant alternatives (IIA) assumption necessary for the application of the (simple) conditional logit model. Thus, nested logit models (NL) were used that partially relax the IIA assumption (Train 1998, Hensher et al. 2005, p. 518). Suitable NL model structures were identified, and the corresponding models estimated with NLOGIT 3.08 www.limdep.com). The inclusive value was set to 1.0 for the degenerated branch, and the model initiated with starting values obtained from a non-nested NL model (Hensher et al. 2005, p. 530). All scale parameters were normalized at the lowest level (random utility level 1, RU1). As model statistics we report adjusted pseudo- $\mathrm{R}^{2}$ values in relation to a 'constants only' model. Values between 0.06 and 0.07 correspond to $\mathrm{R}^{2}$ values of 0.19 and 0.22 in relation to their ordinary least squares equivalents (Hensher et al. 2005, p. 338).

To test for influences of socio-demographic variables on choices, interaction terms of the ASC and of the climate change mitigation attribute were generated (see Table 5). The improved model was generated stepwise by initially including all statistically 'significant' interaction terms from single interaction models and then
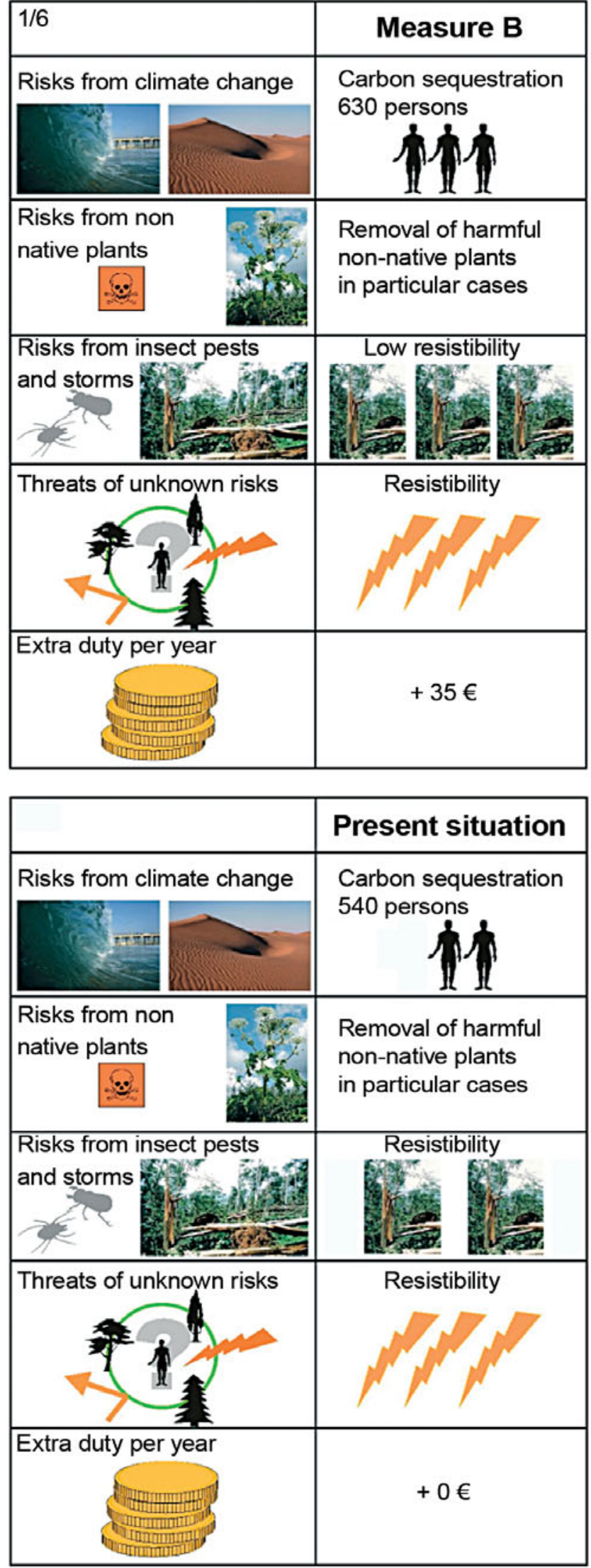
deleting non-significant interaction terms one by one. Significant interaction terms of socio-demographic variables and the climate change mitigation attribute are presented in the improved model (see Table 5).

Statistically significant attribute coefficients allow for the calculation of respondent WTP for attribute level changes. For attributes linear in parameters, the mWTP equals the negative ratio of the respective attribute coefficient $c_{\mathrm{z}}$ and the coefficient of the monetary attribute $c_{\mathrm{y}}$ :

$$
\operatorname{mWTP}=-\frac{C_{\mathrm{z}}}{C_{\mathrm{y}}}
$$

All WTP values given in Table 4 refer to a marginal one-level change in the attributes. For the 20 respondents $(6.62 \%$ of interview respondents) protesting the choice experiment, $\mathrm{mWTP}=0$ was assumed.

\section{EMPIRICAL RESULTS}

\subsection{Socio-demographic characteristics of respondents}

The gender ratio of respondents was 49:51 (female: male; Table 3 ). The youngest respondent was 18 yr old, the oldest was 92 yr. The majority of respondents (45\%) had a secondary school certificate and received a salary (47 to $52.2 \%$ ). Average monthly net income was $1125 €$ per person. Socio-demographic key variables were close to state and national averages (Fig. 3;

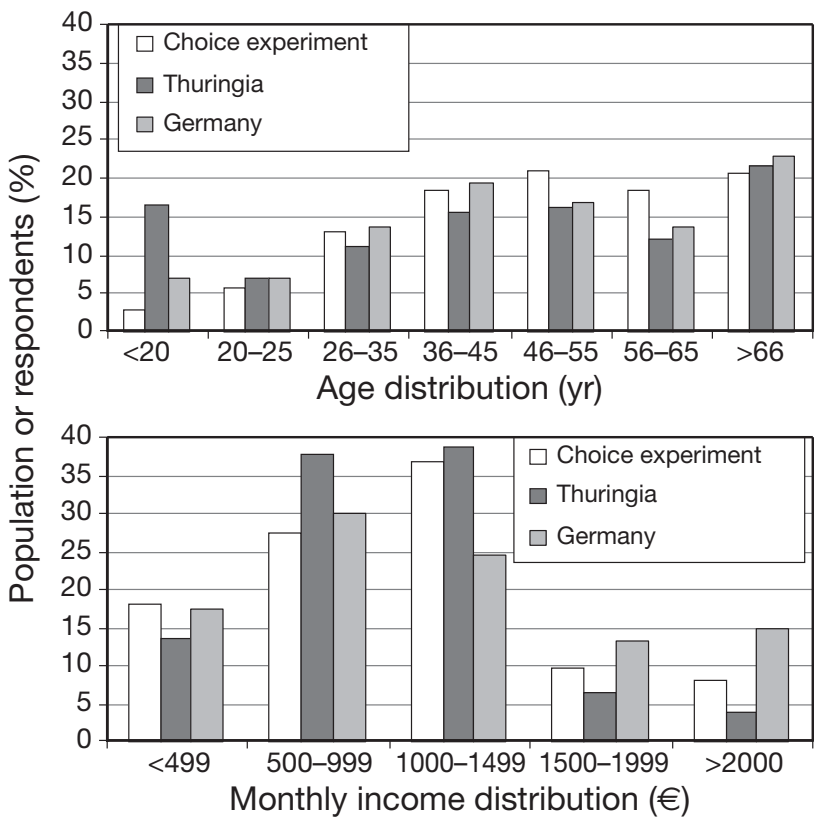

Fig. 3. Age and income distribution of choice experiment respondents (white bars, $\mathrm{n}=282$; this study), and of the populations of Thuringia (dark grey bars; Thüringer Landesamt für Statistik 2008), and Germany (light grey bars; Statistisches Bundesamt 2008)

Thüringer Landesamt für Statistik 2008, Statistisches Bundesamt 2008). For park usage, $86 \%$ of respondents had visited Hainich NP at least once. On average, respondents visited the park 14 times per year.

Table 3. Socio-demographic characteristics of respondents

\begin{tabular}{|c|c|c|}
\hline Variable & Description & Results (SD) \\
\hline Gender & $\begin{array}{l}\text { Dummy variables describing gender of respondents } \\
{[0: \text { female; } 1 \text { : male] }}\end{array}$ & $49 \%$ women, $51 \%$ men \\
\hline Age & Age in years & $50.27 \mathrm{yr}$ (16.95) [between 18 and $92 \mathrm{yr}$ ] \\
\hline Education & $\begin{array}{l}5 \text { point score to describe formal educational level } \\
\text { attained [1: None; 2: general education school level; } \\
\text { 3: secondary school level; } 4 \text { : A-level; } 5 \text { : university of } \\
\text { applied sciences }^{\text {a }} \text { degree or university degree] }\end{array}$ & $\begin{array}{l}19 \% \text { general education school level; } \\
45 \% \text { secondary school level; } 12 \% \text { A-level; } \\
24 \% \text { university of applied sciences } \\
\text { degree or university degree }\end{array}$ \\
\hline Occupation & $\begin{array}{l}\text { Dummy variables to describe occupation status } \\
\text { [1: employed; } 1 \text { : self-employed; } 0 \text { : unemployed, } \\
\text { 0: in training/student, 0: retired; 0: homemaker] }\end{array}$ & $\begin{array}{l}\text { Active work force (employed, self- } \\
\text { employed) } 52.2 \% \text {; other (unemployed, in } \\
\text { training/student, retired, homemaker) } 47.8 \%\end{array}$ \\
\hline Income & 7 categories from $<500$ to $>4000 € \mathrm{mo}^{-1}$ person $^{-1}$ & $1125 € \mathrm{mo}^{-1}$ person $^{-1}(760.5 €)$ \\
\hline Residence & $\begin{array}{l}\text { Dummy variable describing residence of respondents } \\
{[0: \text { rural; } 1: \text { urban] }}\end{array}$ & $31.6 \%$ urban, $68.4 \%$ rural resident \\
\hline NP user status & $\begin{array}{l}\text { Dummy variable if respondent was at least once in } \\
\text { Hainich NP [0: no; } 1: \text { yes] }\end{array}$ & $86 \%$ visited Hainich NP at least once \\
\hline Frequency of NP visits & Frequency of visiting Hainich NP $\mathrm{yr}^{-1}$ & 14.01 visits $\mathrm{yr}^{-1}(38.2)$ \\
\hline
\end{tabular}




\subsection{Importance of attributes for respondents}

According to the results of our survey, $91.4 \%$ of respondents rated the attribute climate change mitigation by carbon sequestration as very important to rather important. $80.5 \%$ of respondents rated the attribute climate change adaptation by pest and storm resilience as very important or rather important. General ecosystem resilience was rated by $68.5 \%$ of respondents as very important to rather important. $55.3 \%$ of respondents rated climate change adaptation towards invasive plants as very important to rather important.

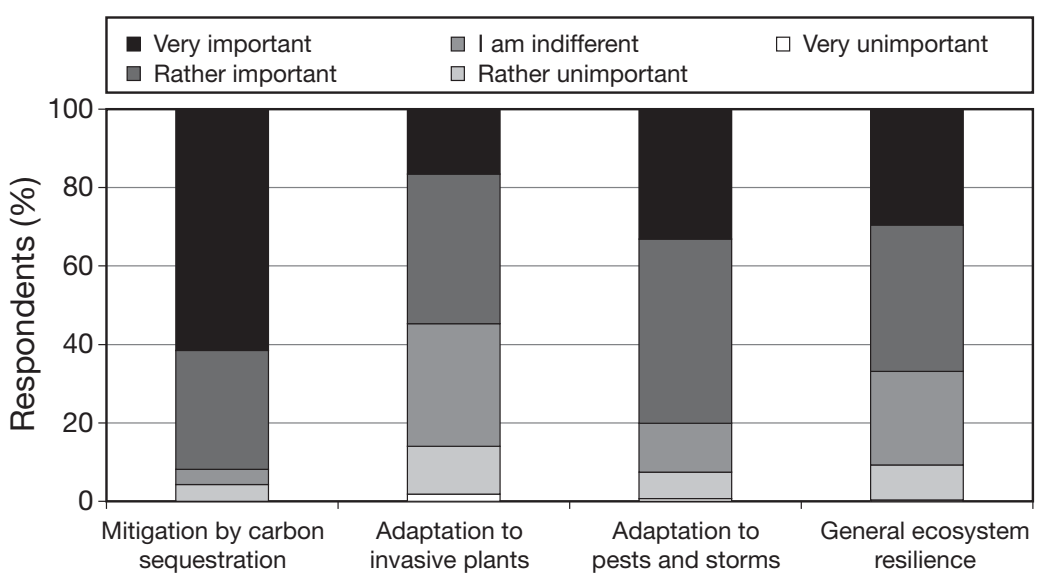

Fig. 4. Importance of climate change mitigation and adaptation rated by respondents

\subsection{Base model results}

The model is overall most highly significant ( $\mathrm{p}$ chisquared $<0.0001 ; \mathrm{df}=7$ ). All attributes are significant determinants of choice; 4 attributes (including cost) at $\mathrm{p}<0.001$ and 1 attribute at $\mathrm{p}<0.05$ (Table 4). Before correction for protest responses, mWTP values for a 1-level change in attributes range from 27.54 to -9.59 €. While respondents supported afforestation, increasing protection levels against pest and storms, and better general ecosystem resilience, more aggressive measures to reduce potential threats from invasive plants were disliked (negative WTP). Climate change adaptation to the risks from pests and storms had the highest mWTP (27.54 €). For climate change mitigation, mWTP was $21.43 €$, for general ecosystem resilience it was almost $17 €$. Compared to the current practice of selective removal of harmful invasive plants, more aggressive removal schemes including removal of plants without known dangers were valued less $(\mathrm{mWTP}=-9.59 €)$. When including protest responses (WTP $=0 €$ ), slightly lower mWTP values are obtained $(6.62 \%$ of respondents protested).

Taking WTP values corrected for protest responses into account, a shadow price for C-sequestration related to personal emissions can be calculated. Based on the mWTP value for a 1-level change of $20.01 € \mathrm{yr}^{-1}$ divided by $\sim 2.7 \mathrm{t} \mathrm{C}$ emissions per year, a shadow price of $7.34 € \mathrm{t} \mathrm{t}^{-1} \mathrm{yr}^{-1}$ is calculated.

\subsection{Model interactions: influences of} socio-demographic characteristics of respondents

Age, gender and education were concurrently interacted with the afforestation attribute (climate change mitigation) and the $\mathrm{ASC}_{i} 4$ interactions were signifi-

Table 4. Nested logit estimation results of the base model. Willingness-to-pay (WTP) values refer to a 1-level shift of each attribute; $\mathrm{n}=282$; for attribute measures/indicators and codings, see Table 2. Marginal WTP: WTP of a marginal unit of the attribute, i.e. of one attribute level difference as coded in Table 2; Corrected marginal WTP: corrected for protest responses counted as stating a WTP of $0 €_{;}$Status-quo-ASC: alternative Specific Constant with respect to the status quo option (coded 1$) .{ }^{* *} p<0.05 ;{ }^{* * *} p<0.001$

\begin{tabular}{|c|c|c|c|c|}
\hline Attribute & Coefficient & $\mathrm{SE}$ & $\begin{array}{l}\text { Marginal WTP } \\
\left(€ \mathrm{yr}^{-1} \text { person }^{-1}\right)\end{array}$ & $\begin{array}{c}\text { Corrected marginal WTP } \\
\left(€ \mathrm{yr}^{-1} \text { person }^{-1}\right)\end{array}$ \\
\hline \multicolumn{5}{|l|}{ Climate change mitigation } \\
\hline Afforestation/100 & $0.3537^{* * *}$ & 0.0466 & 21.43 & 20.01 \\
\hline \multicolumn{5}{|l|}{ Climate change adaptation } \\
\hline Invasive plants & $-0.1582^{* *}$ & 0.0711 & -9.59 & -8.96 \\
\hline Pests and storms & $0.4545^{* * *}$ & 0.0476 & 27.54 & 25.72 \\
\hline General ecosystem resilience & $0.2777^{* * *}$ & 0.0462 & 16.83 & 15.72 \\
\hline Status quo-ASC & $-2.2740^{* * *}$ & 0.5068 & -137.80 & -128.68 \\
\hline Cost & $-0.0165^{* * *}$ & 0.0014 & na & na \\
\hline Log-likelihood & -2257.510 & & & \\
\hline Chi-squared & 1041.248 & & & \\
\hline Pseudo- $\mathrm{R}^{2}$ & 0.0621 & & & \\
\hline Observations (n) & 2256 & & & \\
\hline
\end{tabular}


Table 5. Nested logit estimation results of the improved model. ${ }^{*} \mathrm{p}<0.05 ;{ }^{* *} \mathrm{p}<0.01 ;{ }^{* * *} \mathrm{p}<0.001 ; \mathrm{n}=282$

\begin{tabular}{|lcc|}
\hline Variable & Coefficient & $\mathrm{p}$ \\
\hline Climate change mitigation & & \\
Afforestation/100 & $0.3297^{* * *}$ & 0.0000 \\
Afforestation $\times$ age & $0.1111^{* *}$ & 0.0088 \\
Afforestation $\times$ gender & & \\
$\quad$ (male $=1$ ) & $-0.1538^{* * *}$ & 0.0004 \\
Climate change adaptation & & \\
Invasive plants & $-0.1586^{*}$ & 0.0186 \\
Pests and storms & $0.4191^{* * *}$ & 0.0000 \\
General ecosystem & & \\
$\quad$ resilience & $0.2481^{* * *}$ & 0.0000 \\
Status quo-ASC & $-1.2635^{* * *}$ & 0.0000 \\
Status quo-ASC $\times$ age & $0.3008^{* * *}$ & 0.0000 \\
Status quo-ASC $\times$ education & $-0.1238^{*}$ & 0.0174 \\
Cost attribute & $-0.0157^{* * *}$ & 0.0000 \\
Log-likelihood & -2230.352 & \\
Chi-squared & 1095.564 & \\
Pseudo-R & \\
Observations & 0.07252 & \\
\hline & 2256 & \\
\hline
\end{tabular}

cant at least at the $5 \%$ level. The interaction between age and climate change mitigation ( $p<0.01$; Table 5) shows that age (coded in years between 18 and 92) has a positive effect on higher preferences for the proposed climate change mitigation measures (if an improvement measure is chosen). The interaction between gender and climate change mitigation shows that women (women coded ' 0 '; men coded ' 1 ') have stronger preferences for the proposed climate change mitigation measures $(p<0.001)$. For status-quo-ASC $\times$ age, age has a positive effect on the probability for the current situation (status quo) being chosen ( $p<0.001)$. For status quo-ASC $\times$ education, the lower the education level, the higher the probability that the current situation (status quo) will be the choice $(p<0.05)$.

\section{DISCUSSION}

We conducted a CE on one climate change mitigation and 3 climate change adaptation attributes focusing on forest ecosystem biodiversity. Extensive qualitative preliminary studies (Rajmis \& Barkmann 2007) had shown that respondents are sufficiently aware of the topics covered by our choice experiment attributes. To ensure understanding, attribute level details and wording were designed to reflect respondent previous knowledge on climate change risks as well as forestbased adaptation and mitigation measures. Furthermore, the CE was conducted as a face-to-face survey based on sampling procedures that achieved a good socio-demographic match of respondents with population means (Fig. 3). The low number of respondents who protested the CE $(\mathrm{n}=20 ; 6.62 \%)$ further supports our positive interpretation of the validity of the instrument with regard to the critical issue of respondent familiarity with ecosystem service-type CE attributes (cf. Barkmann et al. 2008).

Supporting content validity, all attributes are significant determinants of choice and display meaningful (signs of the) attribute utility coefficients (see Bateman et al. 2002, p. 363). WTP for climate change mitigation and adaptation ranges between -8.96 and $25.72 € \mathrm{yr}^{-1}$ respondent $^{-1}$ for a one-level change (cf. Table 2). The strongest WTP of $25.72 € \mathrm{yr}^{-1}$ respondent $^{-1}$ was identified for a 1-level change of climate change adaptation towards pests and storms. An independent importance rating of the attributes by respondents before actually making the choice shows that mWTP follows the importance rating for most attributes (cf. Table 4 \& Fig. 4).

The ASC value regarding climate change measures in the Hainich forest area indicates that respondents have strong preferences for improving the status quo beyond what is depicted by the proposed measures displayed in the choice cards (negative ASC coefficient). Such a positive view is stronger with younger respondents (positive sign of interaction term ASC $\times$ age) and for better-educated respondents (negative sign of interaction term ASC $\times$ education). These results do not give any indication that choosing the status quo option was used simply to avoid making a decision at zero cost by respondents. This would have constituted a so-called status quo 'bias' casting doubts on the results. The positive valuation of the proposed scenarios beyond explicitly depicted attributes also shows that respondents do associate additional, implicit benefits with the proposed measures. Certainly, we cannot categorically exclude that such implicit benefit assignments also influenced the valuation of the explicit mitigation and adoption attributes. Still, the material and statistical significance of the coefficient of the ASC terms supports the notion that the majority of such benefits were actually captured by the ASC terms, and consequently do not interfere with the interpretation of the calculated mWTP for the climate change mitigation and adaptation attributes.

Viscusi \& Zeckhauser (2006) found a mean WTP of $0.32 €$ per gallon of gas to eliminate the risks of climate change for a 30 yr period. Similarly, Reiner et al. (2006) asked how much respondents would pay on top of their existing electric bill to 'solve global warming'; $90 \%$ of respondents were willing to pay a maximum of $32 €$ per month, $\left(<400 € \mathrm{yr}^{-1}\right)$. When the Viscusi \& Zeckhauser (2006) result is converted into WTP per $\mathrm{t} C$ in fuel, this represents about $140 € \mathrm{t}^{-1}$ and about $170 €$ per average fuel consumption 2005 per vehicle (calculation based 
on US Department of Transportation 2008). This is much higher than the shadow price for the sequestration of $1 \mathrm{t} \mathrm{C}$ emitted in our results (7.34 € t C emitted person $^{-1} \mathrm{yr}^{-1)}$. These values cannot be directly compared, however, because the first value constitutes WTP for a fuel tax that eliminates the risks of climate change (and its potentially catastrophic negative effects) while our study proposes the much less ambitious effect of reducing one's own net carbon footprint. If we interpret the total documented WTP in our study for a 1-level improvement of climate change mitigation and adaptation measures including the status quoASC (see Table 4), WTP $=190 €$ person $^{-1} \mathrm{yr}^{-1}$. As an equivalent to 'stopping climate change' or 'solving global warming', this value is similar to the one implied by Viscusi \& Zeckhauser (2006). In any case, our WTP-values are much lower than those in the study by Reiner et al. (2006).

Alavalapati et al. (2004) investigated benefits for 3 environmental attributes (C-sequestration, water quality, wildlife habitats in silvopasture). Average WTP for moderate improvements in all 3 environmental attributes was $\sim 94 € \mathrm{yr}^{-1}$ per household for a $5 \mathrm{yr}$ program. For our 4 attributes, a 1-level improvement results in a total WTP of $\sim 60 €$. Annual WTP for C-sequestration alone is estimated at between $\sim 39.5$ and $\sim 42.7 €$ by Alavalapati et al. (2004), and between $\sim 20$ and $\sim 40 €$ in our study (1- or 2-level improvement). Thus, WTP for C-sequestration alone appears lower in our study, but for all mitigation and adoption options it is higher, however, again lower than Alavalapati et al.'s (2004) more inclusive bundle of environmental improvements (including carbon sequestration, water quality and wildlife habitat in silvopasture). Additionally, some of the unexplained preferences for improvements over the status quo in our data (see Section 4.3) may have been attributable to specific attributes if we had also used attributes with a wider scope, including e.g. water quality and wildlife habitat. As actual values at each of these levels of comparison differ by less than a factor of 2, we interpret our data as generally supporting the findings of Alavalapati et al. (2004).

In summary, several studies including this one, document substantial citizen WTP for additional climate change mitigation and/or adaptation measures. The paucity of empirical data and the diversity of approaches do not allow for a definite conclusion over the absolute level of citizen WTP for climate change mitigation and/or adaptation. Even much more elaborate attempts to compare studies than accomplished here, e.g. accounting for temporal differences in real

${ }^{2}$ We thank one of the anonymous reviewers for his comment on this issue purchasing power and socio-economic differences between studies and samples, will suffer from the incompatibility of the units by which $\mathrm{C}$-sequestration is quantified. While this may not be completely avoidable, we recommend that future studies include a best estimate of WTP per t C additionally sequestered per person per year.

Most importantly, when comparing the few data sets available it must be kept in mind that the specific benefits associated with mitigation or adaptation options to be valued may influence value statements. We have discussed several examples above. Furthermore, our study differs from existing work in its community focus. Respondents are faced with mitigation and adaptation options to be implemented in the Hainich forest region, a local leisure and tourism area frequently visited by $86 \%$ of respondents. This means that respondents directly benefit from the proposed adaptation options. If we had proposed to implement them further away, lower stated preferences would be expected for other forests in Germany or abroad ${ }^{2}$.

Finally, the regional setting of our study has an interesting side-effect in relation to nature conservation concerns. Because all mitigation and adoption options presented rest on improvement of forest biodiversity, our results highlight potential regional synergies between climate change and conservation policy. These synergies most likely do not exist for alternative climate change mitigation measures such as the production of agricultural biofuels (Reijnders 2009, Pineiro et al. 2009).

Acknowledgements. We thank the Deutsche Forschungsgemeinschaft (DFG Graduiertenkolleg 1086) for funding, our research assistants, the survey participants, Hainich area respondents for collaboration - especially M. Großmannand $\mathrm{M}$. Harcken for language editing, and 3 anonymous reviewers for helpful comments.

\section{LITERATURE CITED}

Adamowicz W, Louviere J, Swait J (1998a) Introduction to attribute-based stated choice methods. Advanis Inc. for the National Oceanic and Atmospheric Administration, US Departement of Commerce, Washington, DC

Adamowicz W, Boxall P, Williams M, Louviere J (1998b) Stated preference approaches to measuring passive use values. Am J Agric Econ 80:64-75

Alavalapati JRR, Shrestha RK, Stainback GA, Matta JR (2004) Agroforestry development: an environmental economic perspective. Agrofor Syst 61:299-310

Australian Greenhouse Office (2004) Economic issues relevant to costing climate change impacts. Marsden Jacob Associates for the Australian Greenhouse Office. Accessed 21 July 08, www.greenhouse.gov.au/impacts/ publications/costing.html

Balser TC, Kinzig AP, Firestone MK (2002) Linking soil microbial communities and ecosystem functioning. In: Kinzig AP, Pacala SW, Tilman D (eds) The functional conse- 
quences of biodiversity. Princeton University Press, Princeton, NJ, p 265-293

Barkmann J, Marggraf R (2007) Weil wir Geld nicht essen können: zur ökologischen Katastrophenvorsorge durch biologische Vielfalt. In: Sandhoff K, Engel A, Ertl G, Linsenmair KE and others (eds) Vom Urknall zum Bewusstsein: Selbstorganisation der Materie. Georg Thieme, Stuttgart, p 175-192 (in German)

Barkmann J, Glenk K, Handi H, Sundawati L, Witte JP, Marggraf R (2007) Assessing economic preferences for biological diversity and ecosystem services at the Central Sulawesi rainforest margin: a choice experiment approach. In: Tscharntke T, Leuschner C, Zeller M, Guhardja E, Bidin A (eds) Stability of tropical rainforest margins. Springer, Berlin, p 181-208

Barkmann J, Glenk K, Keil A, Leemhuis C, Dietrich N, Gerold G, Marggraf R (2008) Confronting unfamiliarity with ecosystem functions: the case for an ecosystem service approach to environmental valuation with stated preference methods. Ecol Econ 65:48-62

Bateman IJ, Carson RT, Day B, Hanemann M and others (2002) Economic valuation with stated preference techniques: a manual. Edward Elgar, Cheltenham

Berk RA, Fovell RG (1999) Public perceptions of climate change: a 'willingness to pay' assessment. Clim Change 41: 413-446

Bot A, Benites J (2005) The importance of soil organic matter. Key to drought: resistent soil and sustained food production. FAO, Rome

Buchmann N, Schulze ED (1999) Net $\mathrm{CO}_{2}$ and $\mathrm{H}_{2} \mathrm{O}$ fluxes of terrestrial ecosystems. Global Biogeochem Cycles 13: 751-760

Bush GW (2001) Text of a letter from the President to Senators Hagel, Helms, Craig, and Roberts. Office of the Press Secretary. Accessed 20 Aug 2007, www.gcrio.org/OnLn Doc/pdf/bush_letter010313.pdf

Chrzan K, Orme B (2000) An overview and comparison of design strategies for choice-based conjoint analysis. Sawtooth Software 2000-2002, Research paper series, www. sawtoothsoftware.com/download/techpap/desgncbc.pdf

Cole DH (2007) The 'Stern review' and its critics: implications for the theory and practice of benefit-cost analysis. Accessed 21 July 2008, http://ssrn.com/abstract=989085

Deckmyn G, Muys B, Garcia Quijano J, Ceulemans R (2004) Carbon sequestration following afforestation of agricultural soils: comparing oak/beech forest to short-rotation poplar coppice combining a process and a carbon accounting model. Glob Change Biol 10:1482-1491

Dighton J (2003) Fungi in ecosystem processes. Dekker, New York

Edwards PJ, Abivardi C (1998) The value of biodiversity: where ecology and economy blend. Biol Conserv 83:239-246

EIA (Energy Information Administration) (2002) Summary of the Kyoto Report: assessment of economic impacts. Accessed 20 Aug 2007, www.eia.doe.gov/oiaf/kyoto/economic. $\mathrm{htm}$

Galvan GA, Burger-Meijer K, Kuiper ThW, Kik C, Scholten OE (2007) Breeding for improved responsiveness to arbuscular mycorrhizal fungi in onion. 3rd QLIF Congress, Hohenheim, Germany, March 20-23, 2007, Accessed 19 March 2008, http://orgprints.org/view/projects/int_conf_ qlif2007.html

Gitay H, Wilson JB, Lee WG (1996) Species redundancy: a redundant concept? J Ecol 84:121-124

Hensher D, Rose J, Greene W (2005) Applied choice analysis: a primer. Cambridge University Press, Cambridge

IPCC (Intergovernmental Panel on Climate Change) (2007)
Climate change 2007: synthesis report. Contribution of Working Groups I, II and III to the Fourth Assessment Report of the Intergovernmental Panel of Climate Change. IPCC, Geneva, Switzerland

> Jaspersen-Schib R, Theus L, Guirguis-Oeschger M, Gossweiler B, Meier-Abt PJ (1996) Acute poisonings with toxic giants in Switzerland between 1966 and 1994. Schweiz Med Wochenschr 126:1085-1098

Jenkinson DS (1971) The accumulation of organic matter in soil left uncultivated. Rothamsted Exp Stat Rep 1970:113-137

> Kernaghan G, Widden P, Bergeron Y, Légaré S, Paré D (2003) Biotic and abiotic factors affecting ectomycorrhizal diversity in boreal mixed-woods. Oikos 102:497-504

> Knohl A, Schulze ED, Kolle O, Buchmann N (2003) Large carbon uptake by an unmanaged old deciduous forest in central Germany. Agric For Meteorol 118:151-167

Korpel Š (1995) Die Urwälder der Westkarpaten. Gustav Fischer, Stuttgart (in German)

Kowarik I (2003) Biologische Invasionen. Neophyten und Neozoen in Mitteleuropa. Ulmer, Stuttgart (in German)

Kromrey H (2006) Empirische Sozialforschung. Modelle und Methoden der standardisierten Datenerhebung und Auswertung. Lucius \& Lucius, Stuttgart

Kutsch W, Steinborn W, Herbst M, Baumann R, Barkmann J, Kappen L (2001) Environmental indication: a field-test of an ecosystem approach to quantify biological self-organization. Ecosystems 4:49-66

Lancaster K (1966) A new approach to consumer theory. J Polit Econ 74:132-157

Levitus S, Antonov JI, Boyer TP, Stephens C (2000) Warming of the world ocean. Science 287:2225-2229

Logan JA, Regniere J, Powell JA (2003) Assessing the impacts of global warming on forest pest dynamics. Front Ecol Environ 1:130-137

McCann KS (2000) The diversity-stability debate. Nature 405: 228-233

McFadden D (1973) Conditional logit analysis of qualitative choice behavior. In: Zarembka P (ed) Frontiers in econometrics. Academic Press, New York, p 105-142

Menkis A, Vasiliauskas R, Taylor AFS, Stenlid J, Finlay R (2007) Afforestation of abandoned farmland with conifer seedlings inoculated with three ectomycorrhizal fungiimpact on plant performance and ectomycorrhizal community. Mycorrhiza 17:337-348

> Meyer P, Tabaku V, von Lüpke B (2003) Die Struktur albanischer Rotbuchen-Urwälder - Ableitungen für eine naturnahe Buchenwirtschaft. Forstwissenschaftliches Centralblatt 122:47-58 (in German, summary in English)

Msangi S, Rosegrant MW, You L (2006) Ex post assessment methods of climate forecast impacts. Clim Res 33:67-97

Mund M (2004) Carbon pools of European beech forests (Fagus sylvatica) under different silvicultural management. PhD dissertation, Georg-August-Universität Göttingen

- Myers N (1996) Environmental services of biodiversity. Proc Natl Acad Sci USA 93:2764-2769

Nordhaus W (2007) The stern review on the economics of climate change. Accessed 21 July 2008, http://nordhaus. econ.yale.edu/stern_050307.pdf

Parmesan C (2006) Ecological and evolutionary responses to recent climate change. Annu Rev Ecol Evol Syst 37:637-669

Perrings (1995a) Ecological and economic values. In: Willis KG, Corkindale JT (eds) Environmental valuation. CAB International, Wallingford

Perrings C (1995b) Biodiversity conservation as insurance. In: Swanson TM (ed) The economics and ecology of biodiversity decline: the forces driving global change. Cambridge 
University Press, Cambridge, p 69-77

Pineiro G, Jobbagy EG, Baker J, Murray BC, Jackson RB (2009) Set-asides can be better climate investment than corn ethanol. Ecol Appl 19:277-282

Pyšek P, Pyšek A (1995) Invasion by Heracleum mantegazzianum in different habitats in the Czech Republic. J Veg Sci 6:711-718

Rajmis S, Barkmann J (2007) Utilisation of grounded theory methodology for the development of a choice experiment: preliminary studies on the insurance value of biodiversity. In: Meyerhoff J, Lienhoop N, Elsasser P (eds) Stated preference methods for environmental valuation: applications from Austria and Germany. Metropolis, Marburg, p 175-202

Reijnders L (2009) Acute View Transport biofuels: Can they help limiting climate change without an upward impact on food prices? Journal of Consumer Protection and Food Safety 4:75-78 (in German)

Reiner DM, Curry TE, Defigueiredo MA, Herzog HJ and others (2006) American exceptionalism? Similarities and differences in national attitudes toward energy policy and global warming. Environ Sci Technol 40:2093-2098

Rejmanek M (2000) Invasive plants: approaches and predictions. Austral Ecol 25:497-506

Rizzo L, Brick JM, Park I (2004) A minimally intrusive method for sampling persons in random digit dial surveys. Public Opin Q 68:267-274

Robertson GP, Vitousek PM (1981) Nitrification potentials in primary and secondary succession. Ecology 62:376-386

Ruddiman WF, Vavrus SJ, Kutzbach JE (2005) A test of the overdue-glaciation hypothesis. Quat Sci Rev 24:1-10

Statistisches Bundesamt (2008) Population of Germany, age and income distribution. Non-published database available upon request (Excel data sheet) (in German)

Stern N (2006) The economics of climate change. The Stern Review. Accessed 01 Aug 2007, www.hm-treasury.gov. uk/stern_review_report.htm

Switzer GL, Shelton MG, Nelson LE (1979) Successional development of the forest floor and soil surface on upland sites of the East Gulf Coastal Plain. Ecology 60:1162-1171

Talbot JM, Allison SD, Treseder KK (2008) Decomposers in disguise: mycorrhizal fungi as regulators of soil C dynamics in ecosystems under global change. Funct Ecol 22: 955-963

Thüringer Landesamt für Statistik (2008) Population of Thuringia, age and income distribution. Non-published database available upon request (Excel data sheet)

Tol RSJ (2007) The social cost of carbon: trends, outliers and catastrophes. Economics: the open-access, open-assessment E-journal. Accessed 21 July 08 www.economicsejournal.org/economics/discussionpapers/2007-44

> Train K (1998) Recreation demand models with taste differences over people. Land Econ 74:230-240

US Department of Transportation (2008) Motor vehicle fuel consumption and travel in the U.S., 1960-2005. Accessed 15 August 2008, www.infoplease.com/ipa/A0004727.html

Viscusi WK, Zeckhauser RJ (2006) The perception and valuation of risks of climate change: a rational and behavioral blend. Clim Change 77:151-177

WBGU (German Advisory Council on Global Change) (2000) World in transition: strategies for managing global environmental risks. Springer, Berlin

Williamson JA, Forbes JC (1982) Giant Hogweed (Heracleum mantegazzianum): its spread and control with glyphosate in amenity areas. Proc British Crop Protection Conference: Weeds, Brighton, p 967-972

> Yachi S, Loreau M (1999) Biodiversity and ecosystem productivity in a fluctuating environment: the insurance hypothesis. Proc Natl Acad Sci USA 96:1463-1468

Zebisch M, Grothmann T, Schröter D, Haße C, Fritsch U, Cramer W (2005) Klimawandel in Deutschland. Vulnerabilität und Anpassungsstrategien klimasensitiver Systeme. Potsdam-Institut für Klimafolgenforschung, Potsdam

Zelek CA, Shively GE (2003) Measuring the opportunity cost of carbon sequestration in tropical agriculture. Land Econ 79:342-354

Appendix 1. Background and calculations on WTP for additional sequestration of one ton self-emitted carbon being sequestered by afforestation measures (see Table 2 for measures)

\section{Description of Status Quo calculation}

Hainich NP has around 7600 ha; the whole Hainich forest area is about 16000 ha. In the current situation (status quo) long-term $\mathrm{C}$ accumulation of forest soils is estimated in a range from 2.4 to $450 \mathrm{~g} \mathrm{~m}^{-2} \mathrm{yr}^{-1}$ (see e.g. Robertson \& Vitousek 1981, Switzer 1979). For a beech stand in Hainich $\mathrm{NP}$, high net carbon uptake values of up to $580 \mathrm{~g} \mathrm{~m}^{-2} \mathrm{yr}^{-1}$ have been measured by Eddy covariance (Knohl et al. 2003). However, if we suggest smaller annual $C$ sequestration rates (e.g. about $9.2 \mathrm{~g} \mathrm{~m}^{-2} \mathrm{yr}^{-1}$ ), the whole Hainich area (16000 ha) would display an annual $\mathrm{C}$ uptake of roughly 1470 t. Converting $\mathrm{C}$ uptake into $\mathrm{CO}_{2}$ equivalents (conversion factor of $1 / 0.2727=3.6$ according due to the relation $\mathrm{C} / \mathrm{CO}_{2}$ and the molecular masses $\mathrm{C}: 12$ and $\mathrm{O}_{2}: 32=12 / 44=$ 0.2727 ), the carbon of about $5400 \mathrm{t} \mathrm{CO}_{2}$ could be sequestered. With an annual $\mathrm{CO}_{2}$ emission of about $10 \mathrm{t}$ person ${ }^{-1} \mathrm{yr}^{-1}$ in Germany, this is equivalent to the $\mathrm{CO}_{2}$ emissions of about 540 citizens.

\section{Description of afforestation measures (Level 1 and Level 2 of the climate change mitigation attribute)}

Deckmyn et al. (2004) found by means of a carbon accounting model that an oak-beech forest reduces $\mathrm{CO}_{2}$ emissions between 6.2 and $7.1 \mathrm{t} \mathrm{CO}_{2} \mathrm{ha}^{-1} \mathrm{yr}^{-1}$ (Deckmyn et al. 2004). Considering the $\mathrm{CO}_{2} / \mathrm{C}$ relation, this is a sequestration rate between $6.2 / 3.6=1.72 \mathrm{t} \mathrm{C} \mathrm{ha}^{-1} \mathrm{yr}^{-1}$ and $1.97 \mathrm{t} \mathrm{C}$ $\mathrm{ha}^{-1} \mathrm{yr}^{-1}$. Sequestration rates by a young beech forest in southern France were estimated at max. 1.46 t C ha-1 $\mathrm{yr}^{-1}$ (Granier et al. 2000).

Calculating with minimum sequestration rates from Deckmyn et al. (2004) of $6.2 \mathrm{t} \mathrm{CO}_{2} \mathrm{ha}^{-1} \mathrm{yr}^{-1}$ (900/6.2), 145 ha would be needed to be afforested to sequestrate annually 245 additional t C. Converted to German citizen $\mathrm{CO}_{2}$ emission equivalents, this equals about 90 average citizen $\mathrm{CO}_{2}$ emissions (difference between status quo and Level 1 and between Level 1 and Level 2). Taking a two level shift in account (from status quo to Level 2), about 290 ha would be needed to be afforested to compensate for 180 persons each emitting $10 \mathrm{t} \mathrm{yr}^{-1}$ 